\title{
Tyrosine nitration site specificity identified by LC/MS in nitrite-modified collagen type IV
}

\author{
Zhen Wang ${ }^{1}$, David C. Paik ${ }^{2,3}$ \\ James P. Dillon ${ }^{2}$ and Elizabeth R. Gaillard ${ }^{1,4}$ \\ ${ }^{1}$ Department of Chemistry and Biochemistry \\ Northern Illinois University \\ DeKalb, IL 60115, USA \\ ${ }^{2}$ Department of Ophthalmology \\ ${ }^{3}$ Department of Medicine \\ Columbia University College of Physicians and Surgeons \\ New York, NY, USA \\ ${ }^{4}$ Corresponding author: Tel, 815-753-6908; \\ Fax, 815-753-4802; E-mail, gaillard@niu.edu
}

Accepted 19 December 2006

Abbreviations: 3-NT, 3-nitrotyrosine; CID, collision induced dissociation; ECM, extra-cellular matrix; MPO, myeloperoxidase; NEG, non-enzymatic glycation; SRM, selected reaction monitoring

\begin{abstract}
Non-enzymatic nitrite induced collagen cross-linking results in changes reminiscent of age-related damage and parallels the well-known model system, non-enzymatic glycation. We have recently observed that nitrite modification of basement mem brane proteins can induce deleterious effects on overlying retinal pigment epithelial cells in studies relevant to age-related macular degeneration. The present work was undertaken in order to confirm 3-nitro-tyrosine (3-NT) as a product of the reaction and to identify the site specificity of nitration in collagen IV, a major component of basement mem branes. Human collagen type IV was modified via incubation with $200 \mathrm{mM} \mathrm{NaNO} 2(\mathrm{pH}=7.38)$ for one week at $37^{\circ} \mathrm{C}$. The modified protein was prepared in 2 different ways, including acid hydrolysis and trypsin digestion for site specificity determination. The samples were analyzed by LC/MS using a $C_{12}$ RP column. Site specificity was determined from tan dem MS/MS data utilizing TurboSEQUEST software and the Swiss-Prot sequence database. 3-NT was detected in protein digests and acid hydrolysates of nitrite modified collagen IV. Positive identification with standard 3-NT was confirmed by identical $R_{t}, \lambda_{\max }$ $=279 \mathrm{~nm}$ and $355 \mathrm{~nm}$, and $\mathrm{m} / \mathrm{z}=\mathbf{2 2 7}$. Analyses of tryptic digests identified four sites of tyrosine ni-
\end{abstract}

tration, $\alpha 1$ (IV)Y348, $\alpha 1$ (IV)Y534, $\alpha 2$ (IV)Y327, and $\alpha 2$ (IV)$Y 1081$. These sites are located in the triple- helical region of the protein and provide clues regarding potential sites for nitrite modification in collagen type IV.

Keywords: 3-nitrotyrosine; Bruch membrane; collagen type IV; inflammation; nitrites

\section{Introduction}

Reactions involving nitrite ion are becoming increasingly recognized as a means through which oxides of nitrogen (including nitric oxide and nitrogen dioxide) exert negative effects on human tissues. Nitrite can act as a reactive substrate for an array of chemical reactions and include interactions with $\mathrm{H}^{+}$ (as nitrous acid), $\mathrm{H}_{2} \mathrm{O}_{2}$ (through heme peroxidase or free metals), and UV light. At least three different reaction pathways are known to occur and have biological significance. First, nitrite can mediate nitrosation reactions through the formation of nitrosonium ion $\left(\mathrm{NO}^{+}\right)$and/or dinitrogen trioxide $\left(\mathrm{N}_{2} \mathrm{O}_{3}\right)$ in acidic electrophilic additions. Secondly, oxo-metal complex formation by heme peroxidase $/ \mathrm{H}_{2} \mathrm{O}_{2}$ or free $\mathrm{Fe} / \mathrm{H}_{2} \mathrm{O}_{2}$ in Fenton-type reactions, can cause nitration through single electron transfer to nitrite forming nitrogen dioxide $\left(\mathrm{NO}_{2} \cdot\right.$ ) (Thomas et al., 2002; Radi, 2004). Finally, hydroxyl radical $(\mathrm{OH} \cdot)$ and nitrogen dioxide $\left(\mathrm{NO}_{2}{ }^{\circ}\right)$ can be produced through the photochemical decomposition of nitrite and is $\mathrm{pH}$ and oxygen dependent (Vione et al., 2002). Thus, nitrite can be involved in both nitrosation as well as nitration reactions. In addition, nitrite has recently been proposed to function as a hypoxic nitric oxide storage and transport molecule via interactions with heme proteins such as hemoglobin and myoglobin (Dejam et al., 2004). Lastly, non-enzymatic agerelated modifications to the extracellular matrix proteins, such as collagen and elastin, by nitrite at physiological $\mathrm{pH}$ have also been studied. Nitrite was found to disrupt elastin structures, cause protein cross-linking and yellowing (Paik et al., 1997; 2001). Based on UV-Vis absorption, the authors also reported that nitrite can modify tyrosine residues in type I collagen and form 3-NT (Paik et al., 2001).

A significant body of current literature has accrued concerning the detection of 3-nitro-tyrosine (3-NT) in human diseases. Phenolic compounds such as tyro- 
sine provide a prime reaction site for nitration reactions. Although there is significant debate as to the nitration species of greatest importance (i.e. peroxynitrite versus nitrite/ $\mathrm{H}_{2} \mathrm{O}_{2}$ ), it is well accepted that 3-NT does form in human tissues (Dedon and Tannenbaum, 2004). Human diseases in which 3NT has been detected are numerous and include atherosclerosis and various neurodegenerative disorders including Alzheimer's dementia (Beckman and Koppenol, 1996; Castegna et al., 2003). Surprisingly, there have been no studies reported that have examined the presence of 3-NT in Bruch's membrane, although tyrosine nitration has been shown to occur in photoreceptor cells (Miyagi et al., 2002). Furthermore, site specificity for tyrosine nitration has been reported for reactions with several different substrates including human serum albumin (Jiao et al., 2001; Nikov et al., 2003; Willard et al., 2003), human angiotensin II (Petersson et al., 2001), and complex I subunits of mitochondrial membranes (Murray et al., 2003). Of note, site specificity data for tyrosine nitration in collagen has not previously been reported.

Type IV collagen is one of several matrix molecules present in basement membranes. This is the only collagen that has been definitively identified in the basement membrane (Linsenmayer, 1991). The interactions at the C-terminal domain of two monomers result in the formation of a dimer. Tetramers can also be formed by interactions at the $\mathrm{N}$-terminal region, resulting in a highly disulfide-cross-linked $7 \mathrm{~S}$ domain. These two types of interactions combine to produce a network-like structure (Timpl et al., 1981). As such, modifications to type IV collagen may alter these three-dimensional organizations. The staining for type IV collagen in Bruch's membrane occurs in a bilaminar fashion, below the RPE cells and around the choriocapillaris (Campochiaro et al., 1986). Because of the close spatial relationship, modifications to type IV collagen could impart deleterious effects on RPE cell behavior. Recent studies indicate that nitrite-modification of basement membrane-like ECM proteins (including collagen type IV) can impart deleterious effects on adjacent epithelial cell function and viability (Wang et al., 2005). The basis for this cell-matrix interaction could involve cell signaling pathways through 3-NT formation. Other investigators have shown that protein nitration of fibronectin, a glycoprotein found in the extracellular matrix, can modulate fibroblast migration (Sato et al., 2001). Baldus et al. have also shown that myeloperoxidase, the enzyme necessary for oxidation of nitrite to $\mathrm{NO}_{2^{*}}$, can accumulate in the subendothelial matrix of vascular tissues to catalyze fibronectin nitration (Baldus et al., 2001).

The following experiments were carried out in order to study nitrite-mediated chemical modifications to one of the important components in basement membranes, collagen IV. The formation of 3-NT by reaction of nitrite with purified collagen type IV was confirmed and specific tyrosine residues that may be modified were identified. Several sites of tyrosine nitration were identified in the $\alpha 1(\mathrm{I})$ and $\alpha 2(I)$ strands of type IV collagen. All sites were located in the helical region of the collagen primary sequence.

\section{Materials and Methods}

\section{Reagents}

Sodium nitrite, acetic acid, $\beta$-mercaptoethanol and Type IV collagen (from human placenta) were purchased from Sigma Chemical Inc. (St. Louis, MO). Sequencing grade modified trypsin was purchased from Promega (Madison, WI). All organic solvents were HPLC grade and bought from Fisher Scientific Co. (Fair Lawn, NJ).

\section{Preparation of nitrite-modified collagen IV}

A suspension of $1 \mathrm{mg} / \mathrm{ml}$ type IV collagen in $200 \mathrm{mM}$ $\mathrm{NaNO}_{2}$ or $200 \mathrm{mM} \mathrm{NaCl}$ solution (used as a control) was prepared. Both $\mathrm{NaCl}$ and $\mathrm{NaNO}_{2}$ were dissolved in $10 \mathrm{mM} \mathrm{pH} 7.4$ phosphate buffer. Samples were incubated in the dark for one week at $37^{\circ} \mathrm{C}$. Excessive salts were removed by dialysis against 10 mM PBS until the solution outside the dialysis tubes was Griess assay (Bell et al., 1963) negative for nitrite modification. Proteins in the dialysis tubes were collected and dried under argon and ready for further analysis.

\section{Enzyme digestion}

The modified and nonmodified type IV collagen was digested by trypsin with an enzyme-to-substrate ratio of $1: 20$ in $\mathrm{pH} 7.4 \mathrm{PBS}$ for $24 \mathrm{~h}$ at $37^{\circ} \mathrm{C}$. The digests were then immediately subjected to LC-MS analysis.

\section{Acid hydrolysis}

Nonmodified and modified collagen IV was hydrolyzed in $6 \mathrm{M} \mathrm{HCl}$ at $110^{\circ} \mathrm{C}$ for $24 \mathrm{~h}$ using homemade glass tubes with Teflon-lined screw caps. Before hydrolysis, deoxygenation of the samples was achieved by three freeze-pump-thaw cycles. After hydrolysis, excess acid was removed using argon and samples were dissolved in $100 \mu \mathrm{H}_{2} \mathrm{O}$ (containing $0.05 \%$ acetic acid) and analyzed by LC-MS. 


\section{High-performance liquid chromatography- electrospray mass spectrometry (LC-ESI/MS)}

HPLC separation was performed using a Synergi Max-RP C12 column $(150 \times 4.6 \mathrm{~mm})$. For the enzyme digested proteins, the LC-mobile phase was $\mathrm{CH}_{3} \mathrm{CN}$ (ACN) balanced with $\mathrm{H}_{2} \mathrm{O}$ (both containing $0.05 \%$ acetic acid) with the following gradients: $0-2 \%$ ACN for $15 \mathrm{~min}, 2-25 \% \mathrm{ACN}$ for $45 \mathrm{~min}, 25-95 \%$ ACN for $50 \mathrm{~min}$ and a flow rate $0.2 \mathrm{ml} / \mathrm{min}$. For acid hydrolysates, the LC mobile phase was ACN balanced with $\mathrm{H}_{2} \mathrm{O}$ (both containing $0.05 \%$ acetic acid) with the following gradients: $1-10 \% \mathrm{ACN}$ for $50 \mathrm{~min}$, $10-60 \%$ ACN for $30 \mathrm{~min}, 60-100 \% \mathrm{ACN}$ for $20 \mathrm{~min}$ and a flow rate $0.2 \mathrm{ml} / \mathrm{min}$.

The conditions for mass spectrometry (Thermo Finnigan LCQ Advantage and Surveyor LC system, San Jose, CA) were: positive polarity, capillary temperature of $200^{\circ} \mathrm{C}$, source voltage of $4.5 \mathrm{kV}$, capillary voltage of $43 \mathrm{~V}$, and tube lens offset of 50 V, M/Z range: 200-1,000 (acid hydrolysis) or 3002,000 (enzyme digest), normalized collision energy of $30 \%$. For enzyme digests, a data-dependent method was used which contains one full MS scan followed by four $\mathrm{MS}^{2}$ scans for the highest four peaks in each full scan. For acid hydrolysates, the method was set to investigate whether 3-nitrotyrosine $\left(\mathrm{m} / \mathrm{z}\right.$ of $[\mathrm{MH}]^{+}$is 227.1$)$ is present in the sample or not. The method contains one zoom scan $\left(\mathrm{m} / \mathrm{z}\right.$ 222.1-232.1), one $\mathrm{MS}^{2}$ scan with a parent mass of 227.1 and a selective reaction monitoring (SRM) scan with a parent mass of 227.1 and a fragment mass of 181.1 . This fragment $(\mathrm{m} / \mathrm{z} 181.1)$ corresponds to the loss of a nitro group.

The possible nitration sites were identified using SEQUEST and Swiss-Protein database. Modified sites were identified based on a mass addition of 45 .
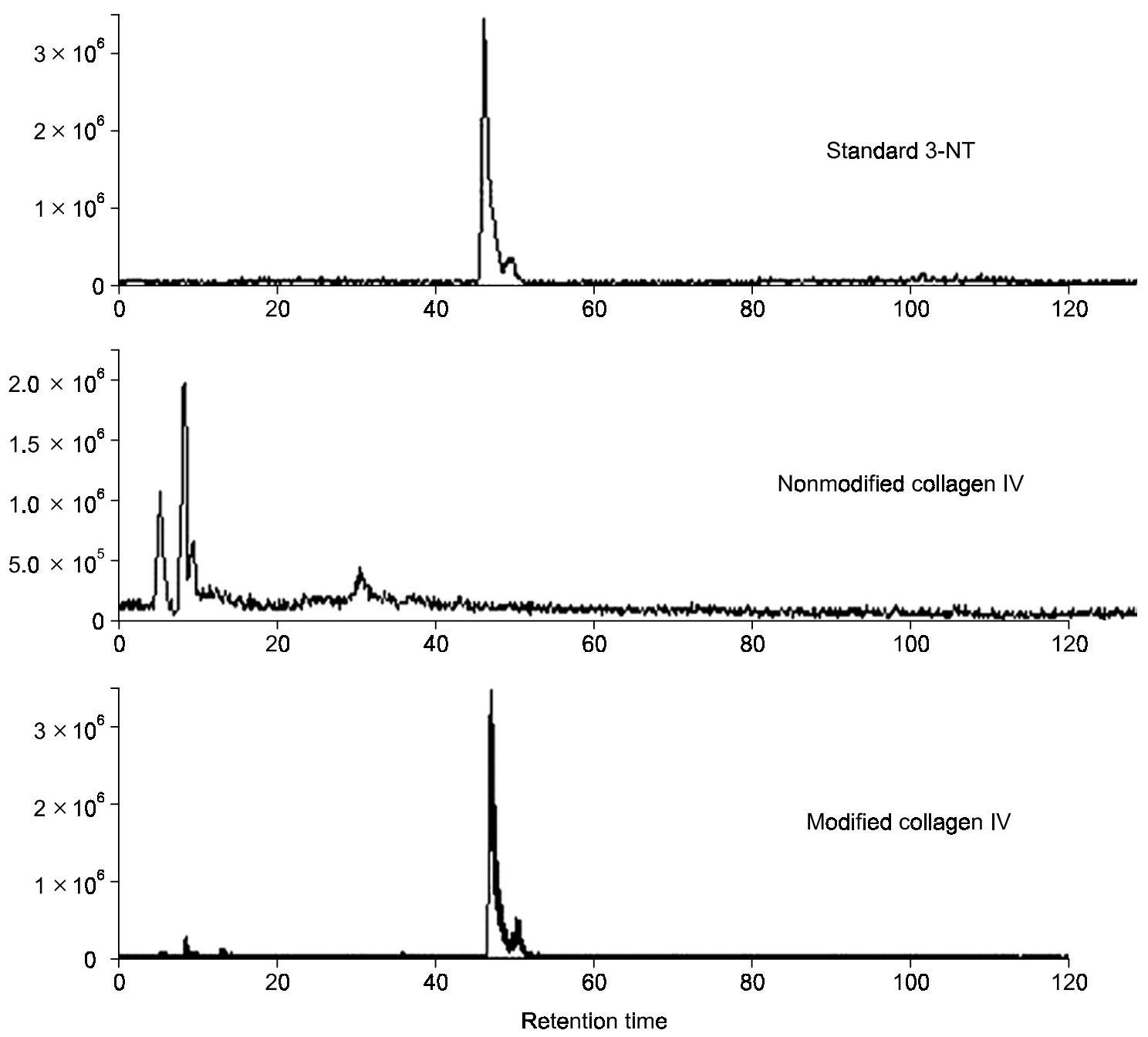

Figure 1. The Zoom Scan chromatogram of 3-NT and the acid hydrolysates of collagen IV ( $\mathrm{m} / \mathrm{z} 224.5-229.5)$. 
Differential modifications were also considered for hydroxylation of proline and lysine. The peptides were assigned as nitrated peptides according to the following requirements:

1) Xcorr filter: $70 \%$ common setting: Xcorr $>1.3$ for +1 charged ions, Xcorr $>1.5$ for +2 charged ions and Xcorr $>2.6$ for +3 charged ions.

2) Amass filters (Sun et al., 2004): MatchPct $>$ $60 \%$ with RACutoff $>20 \%$.

3) PDA output: the absorption spectra at the corresponding retention time is similar to the absorption spectra of 3-NT.

Levels of nitration were estimated by comparing the peak areas in zoom scan or SRM scan chromatograms of acid hydrolysates of modified collagen IV and standard 3-NT. Zoom scan and SRM scan chromatograms were first subjected to seven-point Gaussian smoothing using the Qual Browser Program of the Finnigan Xcalibur 1.3 Software and then integrated after manually choosing peaks that correspond to 3-NT. Standard 3-NT solution with a series of concentrations was injected into LC-MS. The calibration curve was obtained by plotting the peak area versus the mass of 3-NT. The amount of 3-NT in modified collagen was calculated using this calibration curve and the 3-NT peak area in chromatograms of acid hydrolysates.

\section{Results}

Nitrite modified tyrosine residues in collagen IV

In order to study the modifications to collagen IV by nitrite, collagen IV was incubated with nitrite for one week at $37^{\circ} \mathrm{C}$ at physiological $\mathrm{pH}$ (7.4). Following confirmation of complete nitrite removal using a colorimetric nitrite assay (Bell et al., 1963), modified proteins were hydrolyzed by $6 \mathrm{M} \mathrm{HCl}$. Acid hydrolysates were analyzed by LC-MS. The results indicate that tyrosine nitration by reaction with nitrite in collagen IV can form 3-nitrotyrosine (3-NT). Acid hydrolysis was used because 3-NT is stable under acid hydrolysis (Crowley et al., 1998). Figure 1 gives the chromatogram of the zoom scans of different samples. The $\mathrm{m} / \mathrm{z}$ of the quasimolecular ion $\left([\mathrm{MH}]^{+}\right)$ of $3-N T$ is 227.1. The zoom scan monitored the presence of any compound with $\mathrm{m} / \mathrm{z}$ 224.5-229.5. From the analysis of standard 3-NT, it is known that the retention time of $3-\mathrm{NT}$ at this experimental condition is around $47 \mathrm{~min}$. 3-NT in nonmodified collagen IV was not detectable under our experimental condition (Figure 1). Although there were several peaks with $\mathrm{m} / \mathrm{z}$ around 227.1 , the retention times of these peaks were far away from $47 \mathrm{~min}$. A significant amount of 3-NT was present in the acid hydrolysate of nitrite-modified collagen IV (Figure 1).
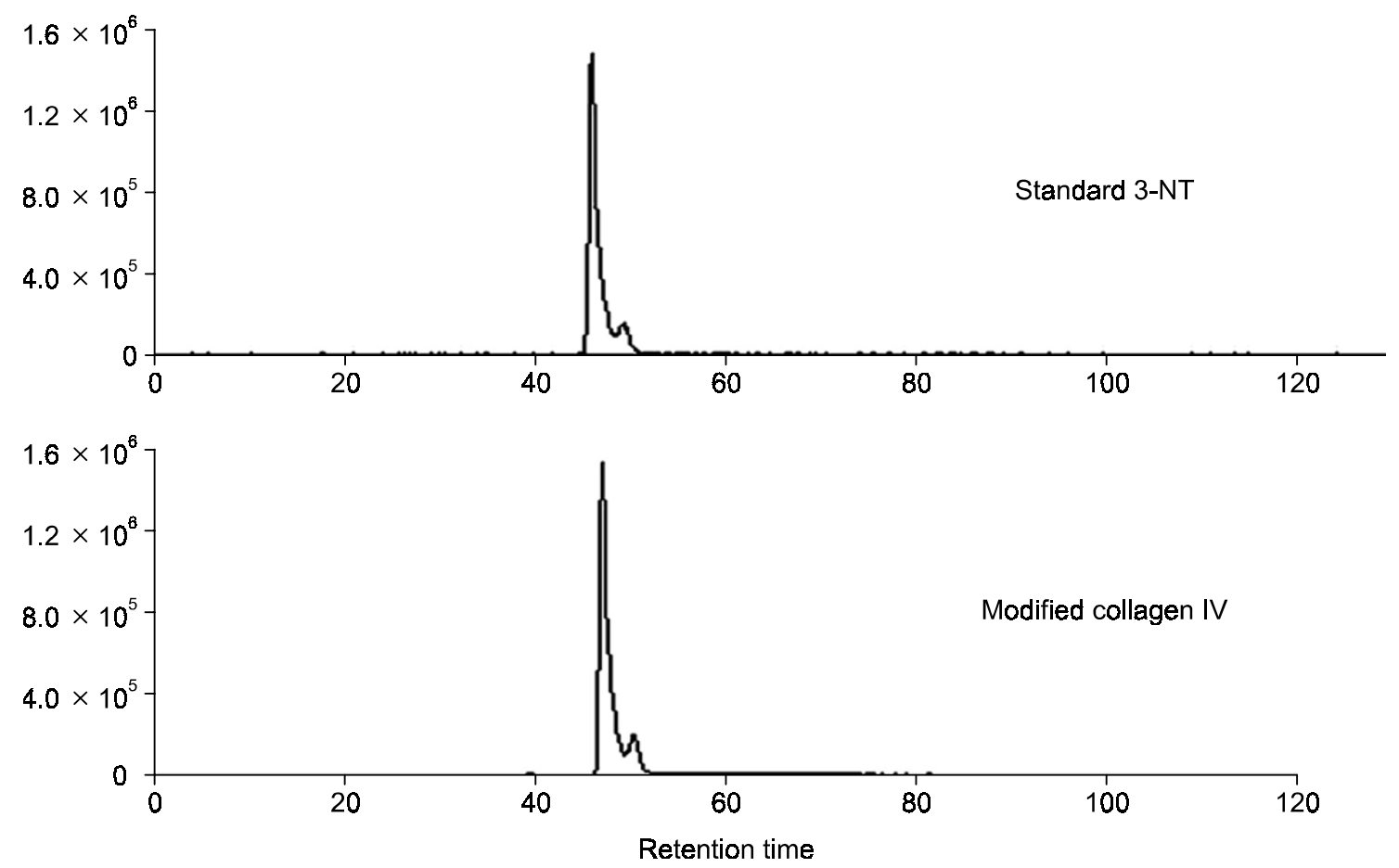

Figure 2. The Selected Reaction Monitoring (SRM) chromatogram of 3-NT and acid hydrolysate of nitrite-modified collagen IV (SRM $227.1 \rightarrow$ 181.1). 


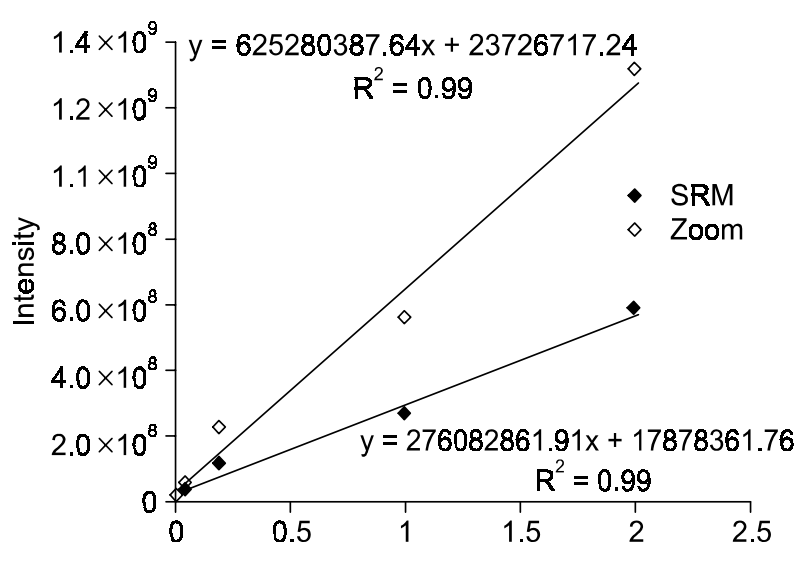

Figure 3. The calibration curves for quantification of 3-NT.
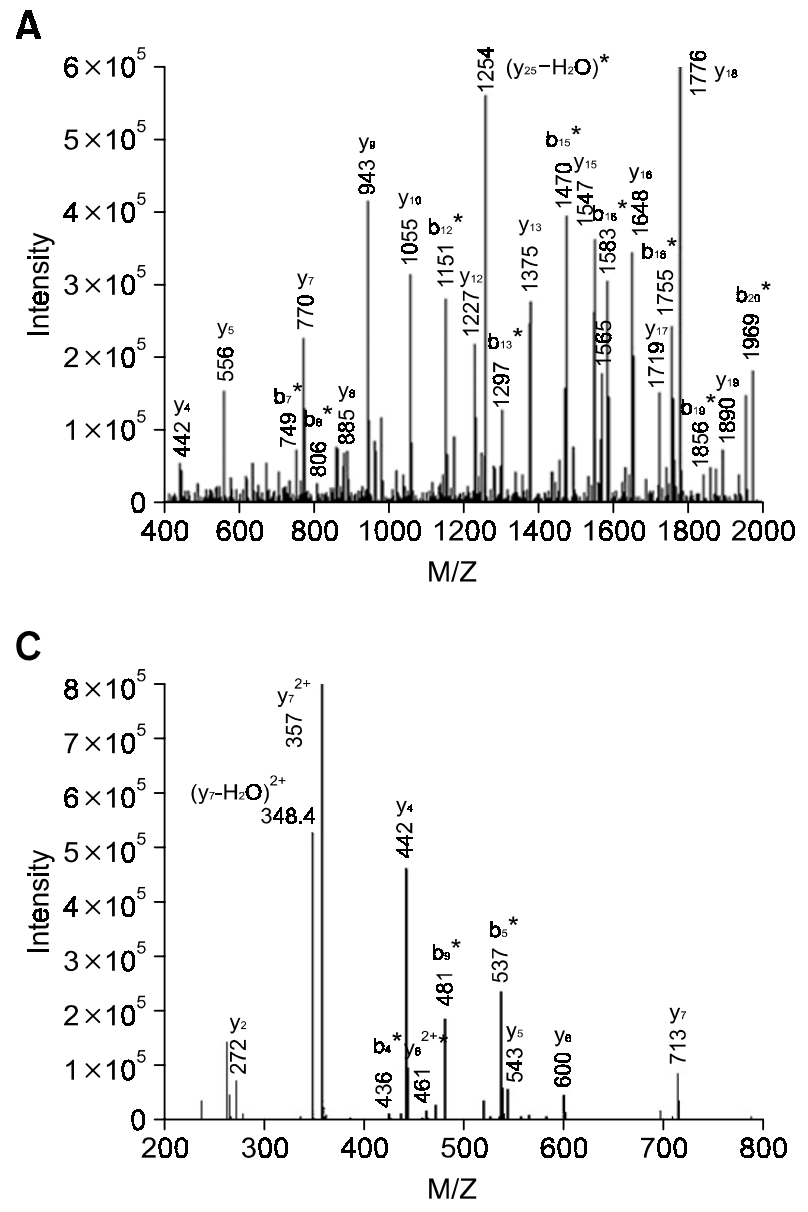

Selected reaction monitoring (SRM) scans were also performed in order to further verify that the peak at retention time $47 \mathrm{~min}$ was in fact, 3-NT. In the SRM mode, the detector was programmed to detect the presence of compounds with a parent ion of 227.1 and one fragment ion of 181.1. 3-NT has a major fragment with $\mathrm{m} / \mathrm{z} 181.1$ which corresponds to the loss of a $-\mathrm{NO}_{2}$ group. The results of the SRM scan are shown in Figure 2. There is a peak in the SRM scan which indicates the presence of 3-NT in the acid hydrolysate of nitrite-modified collagen IV. This result confirms that nitrite modification of collagen IV results in the formation of 3-NT.

In order to quantitate the amount of tyrosine nitration by reaction with nitrite, different concen-

B

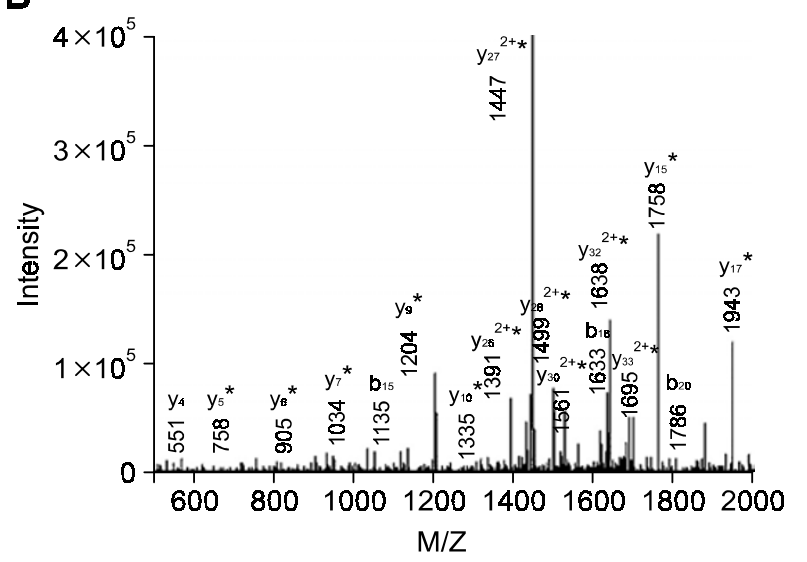

D

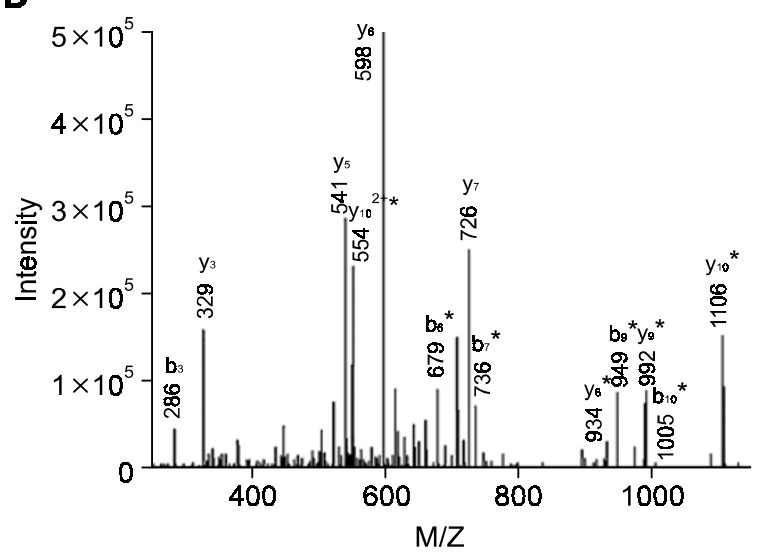

Figure 4. The tandem mass spectra of the modified peptides. The tandem mass spectrum is labeled with the predicted $b$ and $y$ ions. $B$ and $y$ ions consistent with nitration are shown with an asterisk. (A) The identified peptide for this MS/MS spectrum has the following sequence: AGLY\#GEIGATGDFGDIGDTINLPGR. The modified tyrosine is Y1081 in alpha 2 chain of collagen IV. The calculated [M $+2 \mathrm{H}]^{2+}=1240.85$, the experimental $[M+2 H]^{2+}=1240.93$. Xcorr: 6.58 . (B) The identified peptide for this MS/MS spectrum has the following sequence: DGVAGVP@ GPQGTP@GLIGQPGAK@GEP@GEFY\#FDLR. The modified tyrosine is Y534 in alpha 1 chain of collagen IV. The calculated [M $+2 \mathrm{H}]^{2+}=1696.81$, the experimental $[\mathrm{M}=2 \mathrm{H}]^{2+}=1696.56$. Xcorr: 2.83. @ shows the hydroxylation. (C) The identified peptide for this MS/MS spectrum has the following sequence: GY\#P@GTP@GPR. The modified tyrosine is Y348 in alpha 1 chain of collagen IV. The calculated $[\mathrm{M}+2 \mathrm{H}]^{2+}=489.73$, the experimental [M $+2 \mathrm{H}]^{2+}=490.23$. Xcorr: 1.45.@ shows the hydroxylation. (D) The identified peptide for this MS/MS spectrum has the following sequence: GLDGY\#QGPDGPR. The modified tyrosine is Y327 in alpha 2 chain of collagen IV. The calculated $[\mathrm{M}+2 \mathrm{H}]^{2+}=638.79$, the experimental $[\mathrm{M}+2 \mathrm{H}]^{2+}=$ 639.48. Xcorr: 3.04. 
trations of 3-NT solution were injected into the LC-MS. Following analysis, calibration curves were obtained from area calculations of both zoom scans and SRM scans independently. The regression equations for the calibration curves were $y=$ $276082861.91 x+17878361.76$ for SRM scans, and $y=625280387.64 x+23726717.24$ for zoom scans. Utilizing these equations, the amount of 3-NT in the acid hydrolysates of nitrite-modified collagen IV were calculated. Using zoom scan data, the amount of 3-NT in modified proteins was calculated to be 9.35 $\mu \mathrm{g} / \mathrm{mg}$ proteins. Using SRM scan data, the amount of $3-N T$ in modified proteins was calculated to be $10.15 \mu \mathrm{g} / \mathrm{mg}$ proteins. Thus, both methods yield comparable results. Based on the molecular weight of collagen IV and the number of tyrosine residues present in the protein, the relative amount of modified tyrosine residues was estimated to be $40 \%$.

\section{Identification of the sites of modified tyrosine residues}

Trypsin digests of nitrite-modified collagen IV were analyzed by LC-MS. Following each full scan, four tandem mass spectra were obtained for the four highest peaks in each full scan. The MS/MS data were then extracted from the raw file and a SEQUEST algorithm was used to identify the modified peptides. A cross-correlation function (Xcorr) was then provided by SEQUEST to discriminate positive identifications from negative identifications. However, protein identification by the SEQUEST method does not take into account unusual fragmentation events that can occur as a result of the presence of specific residues. For example, the presence of proline residues in a peptide has a significant effect upon the tandem mass spectra. Protonation and cleavage of the proline amide bond by collision induced dissociation (CID) to produce a $y$ type ion is a highly favored process and often dominates the tandem mass spectra (Hunt et al., 1986). As a result, it is difficult to sequence proline-rich proteins by CID mass spectrometry. Because prolines are abundant in collagen, identification of these collagen peptides can be a difficult process. Therefore, when the modified peptides were searched, we decreased the requirement for Xcorr to $70 \%$ of the common setting. In addition, SEQUEST parameters were combined with manual validation and other parameters such as Amass. Based on these methods, four modified peptides were identified. Figure 4 (A-D) give the tandem mass spectra for these identified peptides. The identified sites of tyrosine modification were Y348, Y534 in the $\alpha 1$ chain and $Y 327, Y 1081$ in the $\alpha 2$ chain of collagen IV. All of these residues are in the triple

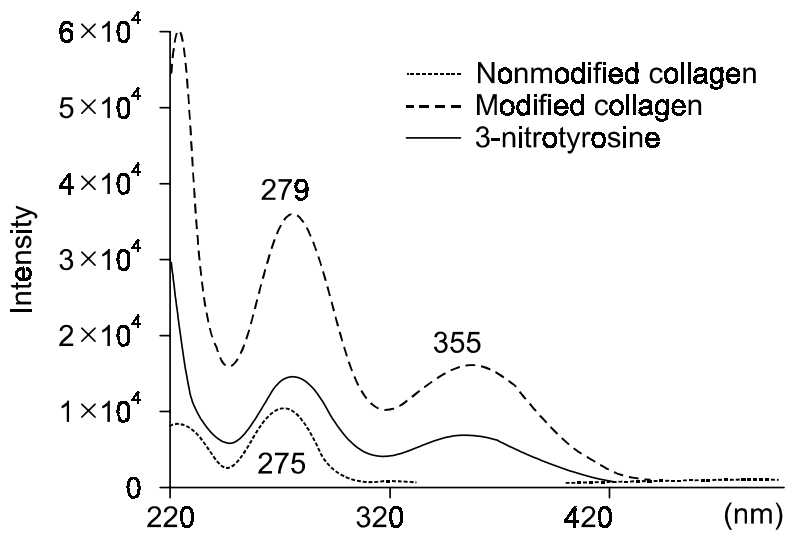

Figure 5. The PDA output at the retention time of the modified peptide $\mathrm{D}$, standard 3-NT and the nonmodified peptides at the same retention time.

helical region of collagen IV. In addition, the absorption spectra for each of the above peptides were similar to that of standard 3-NT, consistent with the presence of 3-NT in each peptide. Figure 5 is an example of the absorption spectrum of one of these peptides.

The most common molecular form of type IV collagen is believed to be a heteropolymeric molecule of the structure $[\alpha 1(\mathrm{IV})]_{2} \alpha 2$ (IV). However, it has also been suggested that the homopolymeric forms $[\alpha 1(\mathrm{IV})]_{3}$ and $[\alpha 2(\mathrm{IV})]_{3}$ occur as well. In addition, at least 4 additional type IV collagen molecules are now known to exist (Linsenmayer,1991). Using Xcorr values chosen to satisfy the common setting, when the database contains $\alpha 1$ or $\alpha 2$ chains only, more than 20 positively matched peptides for each chain were identified. However, when the database contains $\alpha 3, \alpha 4, \alpha 5$, or $\alpha 6$ chains, no peptide matches from the tandem mass spectra of LC-MS analyses were found. This result indicated that the collagen IV used in these experiments was mainly a heteropolymeric molecule of the structure $[\alpha 1(\mathrm{IV})]_{2} \alpha$ 2(IV).

In addition to the four mentioned sites, other tyrosine residues could be modified as well. As mentioned previously, the high abundance of proline in collagen can make the identification of peptides by SEQUEST difficult. When these SEQUEST results were carefully examined, several peptides with low XCorr number (around 1.0), contained matches for all of the high-abundance fragment ions of the tandem mass spectra with some continuity of the b,y ions. Thus, these peptides could have been modified as well. These peptides include Y1107, Y1352 and Y675 in the $\alpha 1$ chain, and $Y 351$ in the $\alpha 2$ chain. 


\section{Discussion}

Collagen IV is an important ECM protein in Bruch's membrane. Post-translational modifications to collagen IV can affect the function of this protein. Our previous experiments indicate that reaction with nitrite increases collagen cross-linking and yellowing (Paik et al., 2001; 2006). In this current study, site specificity of tyrosine nitration in collagen IV has been determined. About $40 \%$ of the available tyrosine residues underwent nitration. Since it is known that there are 18 tyrosine residues in the $\alpha 1$ chain and 13 tyrosine residues in the $\alpha 2$ chain, at least 7 residues in the $\alpha 1$ chain and 5 residues in the $\alpha 2$ chain were modified. There are two reasons why additional, as yet unidentified, sites of tyrosine nitration may exist. The first reason has been described previously and deals with the difficulty of identifying proline-rich peptides by SEQUEST. Second, modification to collagen IV by nitrite results in the formation of covalent cross-links within the protein. Once the protein is cross-linked, the sequence of the protein will be changed. Because SEQUEST utilizes the original protein sequence in order to identify the modified peptides, areas involved in the formation of cross-links that contain sites of tyrosine nitration will not be accurately identified.

Nitration of protein tyrosine residues to form 3-NT is considered a hallmark of tissue injury caused by inflammation. 3-NT has been identified in many diverse pathological conditions such as atherosclerosis, pulmonary and heart disease, viral infections and neurological disorders (Ischiropoulos, 1998). Recent studies have established that in addition to serving as a "marker" of reactive nitrogen species (RNS) formation, nitration of key tyrosine residues can alter the function of proteins. For example, modification of tyrosine residues can affect the phosphorylation and dephosphorylation of tyrosine, an important mechanism of cell regulation (Di Stasi et al., 1999; MacMillan-Crow et al., 2000). In addition, nitration of tyrosine in the rat skeletal- muscle sarcoplasmic reticulum $\mathrm{Ca}^{2+}$ ATP-ase (SERCA2a) enzyme may affect its catalytic activity (Viner et al., 1999). Lastly, incorporation of free 3-NT into proteins through translation has been reported to alter microtubule function (Eiserich et al., 1999).

Despite mounting evidence for the physiologic and pathophysiologic relevance of protein nitration, the mechanisms underlying this modification in vivo are still poorly understood. It was initially believed that 3-NT was formed solely by the reaction of tyrosine with peroxynitrite, a potent oxidant resulting from the diffusion limited reaction of nitric oxide (NO) with superoxide anion $\left(\mathrm{O}_{2}{ }^{-}\right)$(Koppenol et al., 1992). Based on this assumption, 3-NT has been used as a specific biomarker for peroxynitrite production (Moriel and Abdalla, 1997; Hoeldtke et al., 2003). However, investigators have questioned the plausibility of the peroxynitrite mechanism (Fukuto and Ignarro, 1997). For example, tyrosine nitration has been shown to be very inefficient when $\mathrm{NO}$ and $\mathrm{O}_{2}{ }^{-}$are generated at equal rates at physiological $\mathrm{pH}$ (Pfeiffer and Mayer, 1998). Several other peroxynitrite-independent mechanisms for 3-NT formation have been identified (Eiserich et al., 1996; Van der Vliet et al., 1997) and several excellent reviews have been recently published (Bian et al., 2003; Whiteman et al., 2003; Dedon and Tannenbaum, 2004). The myeloperoxidase (MPO) catalyzed nitration has received considerable attention (Van der Vliet et al., 1997; Pfeiffer et al., 2001) and proceeds through a Fenton type mechanism involving one electron oxidation of nitrite to form nitrogen dioxide which then modifies the substrate. MPO is a heme protein abundantly expressed in polymorphonuclear neutrophils and monocytes during inflammation and, thus, $\mathrm{NO}_{2}^{-}$and MPO can be produced simultaneously during an inflammatory process.

In contrast to these previously noted studies, we have focused primarily on the endpoint changes that can occur to long-lived proteins as a result of reaction with nitrite and the effect that this can have on cell and tissue function. Because these modifications are accumulated over decades in the living organism, it is necessary to use nitrite concentrations that are higher than those found under physiological conditions. The maximum serum concentrations that have been reported in the literature are on the order of micromolar concentrations (Radi, 2004). In this regard, we have developed a model system patterned on the well known model system of Non-Enzymatic Glycation (NEG) in which longterm incubations utilizing greater than physiologic concentrations of reactants are used to study effects that could have potentially taken decades to develop.

NEG is a well established aging model system relevant to diabetic-related complications and aging. It is well known that the level of reactants used to study the effects of glycation on connective tissue proteins (i.e. 100-250 $\mathrm{mM}$ ) are well above those encountered in vivo (Kohn et al., 1984; Fu et al., 1994; Winlove et al., 1996). The rationale behind the use of supraphysiologic reactant concentrations is to identify the end-products of the reaction and to simulate functional, biomechanical, and biochemical changes that could take decades to develop in vivo. The work which identified pentosidine as a cross-link biomarker of collagen glycation utilized concentrations of $100 \mathrm{mM}$ pentoses for an incubation period of 6 days (Sell and Monnier, 1989). Subsequently, 
several products of these in vitro incubations have been detected in vivo, including advanced glycation end-products (AGEs) such as pentosidine (Sell and Monnier, 1989; Sims et al., 1996) and the adduct carboxymethyl lysine (Dyer et al., 1993). Thus, the presence of these advanced glycation end-products in vivo have established the biological relevance of NEG and have validated this experimental method as a means for studying long-term chemical effects to connective tissue proteins such as collagens.

Reactions involving nitrous acid, the conjugate acid of nitrite, have been well studied in the past. Electrophilic addition reactions with various substrates including proteins and amino acids were described during the 1970's. During that time, reactions with secondary amines received particular attention since their primary products (i.e. N-nitroso compounds) were found to be highly carcinogenic and mutagenic (Knowles et al., 1974; Ohara et al., 1988). Modifications to proteins by nitrite at neutral $\mathrm{pH}$, in contrast, were not widely studied. This may have been in part due to the fact that the rate of reaction at neutral $\mathrm{pH}$ is very slow. Thus, neutral reactions may not have been thought to be important at that time. However, it is now known that during chronic inflammation, tissues may be exposed to elevated nitrite levels for prolonged periods. Ongoing elevated nitrite exposure at neutral $\mathrm{pH}$ could occur and thus, the reactions at neutral $\mathrm{pH}$ may be relevant to in vivo processes involving long-lived extracellular proteins. It is not clear at this time whether such reactions that are carried out at neutral $\mathrm{pH}$ are in fact occurring through nitrous acid formation. Even at neutral $\mathrm{pH}$, solutions containing high nitrite concentrations will contain small amounts of nitrous acid which could be consumed during reaction incubations. Further study will be required in order to more fully delineate the mechanism of reaction in our model system and in vivo.

Importantly, the results described have indicated that a by-product of inflammation, nitrite, can damage the structure of human basement membranes. Chronic inflammation, a state characterized by increased oxidative and nitrosative stress, has been strongly implicated in the development of AMD. Hageman et al. have clearly identified the BM region as a site of active inflammation (Anderson et al., 2002). Furthermore, recent exciting information concerning the genetics of AMD indicates that alterations in the complement pathway of inflammation plays a major role in the disease (Daiger, 2005). Four independent studies, published this year, implicate complement factor $\mathrm{H}$, an inhibitor of uncontrolled complement activation via the alternative complement pathway (Edwards et al., 2005; Hageman et al., 2005; Haines et al., 2005; Klein et al.,
2005). Upregulation of the alternative pathway of complement activation will promote the formation of reactive nitrogen species (RNS), including by-products of nitric oxide formation, such as nitrite. This would provide a prime environment for the formation of both nitrating and nitrosating species capable of connective tissue protein damage through nonenzymatic collagen cross-linking and elastin fragmentation.

\section{Acknowledgment}

Support was provided in part by Research to Prevent Blindness (JPD, DCP).

\section{References}

Anderson DH, Mullins RF, Hageman GS, Johnson LV. A role for local inflammation in the formation of drusen in the aging eye. Am J Ophthalmol 2002;134:411-31

Baldus S, Eiserich JP, Mani A, Castro L, Figueroa M, Chumley $P$, Ma W, Tousson A, White CR, Bullard DC, Brennan ML, Lusis AJ, Moore KP, Freeman BA. Endothelial transcytosis of myeloperoxidase confers specificity to vascular ECM proteins as targets of tyrosine nitration. J Clin Invest 2001;108:1759-70

Beckman JS,. Koppenol WH. Nitric oxide, superoxide, and peroxynitrite: the good, the bad, and ugly. Am J Physiol 1996;271:1424-37

Bell FK, O'Neill JJ, Burgison RM. Determination of the oil/water distribution coefficients of glyceryl trinitrate and two similar nitrate esters. J Pharm Sci 1963;52:637-8

Bian K, Gao Z, Weisbrodt N, Murad F. The nature of heme/iron-induced protein tyrosine nitration. Proc Natl Acad Sci 2003;100:5712-7

Campochiaro PA, Jerdon JA, Glaser BM. The extracellular matrix of human retinal pigment epithelial cells in vivo and its synthesis in vitro. Invest Ophthalmol Vis Sci 1986;27:1615-21

Castegna A, Thongboonkerd V, Klein JB, Lynn B, Markesbery WR, Butterfield DA. Proteomic identification of nitrated proteins in Alzheimer's disease brain. J Neurochem 2003; 85:1394-401

Crowley JR, Yarasheski K, Leeuwenburgh C, Turk J, Heinecke JW. Isotope dilution mass spectrometric quantification of 3-nitrotyrosine in proteins and tissues is facilitated by reduction to 3-aminotyrosine. Anal Biochem 1998;259: 127-35

Daiger SP. Genetics. Was the human genome project worth the effort? Science 2005;308:362-4

Dedon PC, Tannenbaum SR. Reactive nitrogen species in the chemical biology of inflammation. Arch Biochem Biophys 2004;423:12-22

Dejam A, Hunter CJ, Schechter AN, Gladwin MT. Emerging role of nitrite in human biology. Blood cells Mol Dis 2004; $32: 423-9$ 
Di Stasi AM, Mallozzi C, Macchia G, Petrucci TC, Minetti M. Peroxynitrite induces tryosine nitration and modulates tyrosine phosphorylation of synaptic proteins. J Neurochem 1999;73:727-35

Dyer DG, Dunn JA, Thorpe SR, Bailie KE, Lyons TJ, McCance DR, Baynes JW. Accumulation of Maillard reaction products in skin collagen in diabetes and aging. J Clin Invest 1993; 91:2463-9

Edwards AO, Ritter R, Abel KJ, Manning A, Panhuysen C, Farrer LA. Complement factor $\mathrm{H}$ polymorphism and age-related macular degeneration. Science 2005;308:421-4

Eiserich JP, Cross CE, Jones AD, Halliwell B, van der Vliet A. Formation of nitrating and chlorinating species by reaction of nitrite with hypochlorous acid. A novel mechanism for nitric oxide-mediated protein modification. J Biol Chem 1996;271: 19199-208

Eiserich JP, Estevez AG, Bamberg TV, Ye YZ, Chumley PH, Beckman JS, Freeman BA. Microtubule dysfunction by posttranslational nitrotyrosination of alpha-tubulin: a nitric oxide-dependent mechanism of cellular injury. Proc Natl Acad Sci USA 1999;96:6365-70

Fu MX, Wells-Knecht KJ, Blackledge JA, Lyons TJ, Thorpe $\mathrm{SR}$, Baynes JW. Glycation, glycoxidation, and cross-linking of collagen by glucose. Diabetes 1994;43:676-83

Fukuto JM, Ignarro LJ. In vivo aspects of nitric oxide (NO) chemistry: does peroxynitrite (-OONO) play a major role in cytotoxicity. Acc Chem Res 1997;30:149-52

Hageman GS, Anderson DH, Johnson LV, Hancox LS, Taiber AJ, Hardisty LI, Hageman JL, Stockman HA, Borchardt JD, Gehrs KM, Smith RJ, Silvestri G, Russell SR, Klaver CC, Barbazetto I, Chang S, Yannuzzi LA, Barile GR, Merriam JC, Smith RT, Olsh AK, Bergeron J, Zernant J, Merriam JE, Gold $B$, Dean $M$, Allikmets RA. Common haplotype in the complement regulatory gene factor $\mathrm{H}(\mathrm{HF} 1 / \mathrm{CFH})$ predisposes individuals to age-related macular degeneration. Proc Natl Acad Sci USA 2005;102:7227-32

Haines JL, Hauser MA, Schmidt S, Scott WK, Olson LM, Gallins P, Spencer KL, Kwan SY, Noureddine M, Gilbert JR, Schnetz-Boutaud N, Agarwal A, Postel EA, Pericak-Vance MA. Complement factor $\mathrm{H}$ variant increases the risk of age-related macular degeneration. Science 2005;308:419-21

Hoeldtke RD, Bryner KD, McNeill DR, Hobbs GR, Baylis C. Peroxynitrite versus nitric oxide in early diabetes. Am J Hypertens 2003;16:761-6

Hunt DF, Yates JR, Shabanowitz J, Winston S, Hauer CR. Protein sequencing by tandem mass spectrometry. Proc Natl Acad Sci USA 1986;83:6233-7

Ischiropoulos $\mathrm{H}$. Biological tyrosine nitration: a pathophysiological function of nitric oxide and reactive oxygen species. Arch Biochem Biophys 1998;356:1-11

Jiao K, Mandapati S, Skipper PL, Tannenbaum SR, Wishnok JS. Site-selective nitration of tyrosine in human serum albumin by peroxynitrite. Anal Biochem 2001;293:43-52

Klein R, Zeiss C, Chew EY, Tsai JY, Sackler RS, Haynes C, Henning AK, Sangiovanni JP, Mane SM, Mayne ST, Bracken MB, Ferris FL, Ott J, Barnstable C, Hoh J. Complement factor
$\mathrm{H}$ polymorphism in age-related macular degeneration. Science 2005;308:385-9

Knowles ME, McWeeny DJ, Couchman L, Thorogood M. Interaction of nitrite with proteins at gastric $\mathrm{pH}$. Nature 1974;247:288-9

Kohn RR, Cerami A, Monnier VM. Collagen aging in vitro by nonenzymatic glycosylation and browning. Diabetes 1984;33: 57-9

Koppenol WH, Moreno JJ, Pryor WA, Ischiropoulos H, Beckman JS. Peroxynitrite, a cloaked oxidant formed by nitric oxide and superoxide. Chem Res Toxicol 1992;5:834-42

Linsenmayer TF. Collagen. In Cell biology of Extracellular Matrix (Hay ED, ed), 1991, 31-3, Plenum Press, New York

MacMillan-Crow LA, Greendorfer JS, Vickers SM, Thompson JA. Tyrosine nitration of c-SRC tyrosine kinase in human pancreatic ductal adenocarcinoma. Arch Biochem Biophys 2000;377:350-6

Miyagi M, Sakaguchi H, Darrow RM, Yan L, West KA, Aulak KS, Stuehr DJ, Hollyfield JG, Organisciak DT, Crabb JW. Evidence that light modulates protein nitration in rat retina. Mol Cell Proteomics 2002;1:293-303

Moriel P, Abdalla DS. Nitrotyrosine bound to beta-VLDLapoproteins: a biomarker of peroxynitrite formation in experimental atherosclerosis. Biochem Biophys Res Commun 1997;232:332-5

Murray J, Taylor SW, Qhang B, Ghosh SS, Capaldi RA. Oxidative damage to mitochondrial complex I due to peroxynitrite. Identification of reactive tyrosines by mass spectrometry. J Biol Chem 2003;278:37223-30

Nikov G, Bhat V, Wishnok JS, Tannenbaum SR. Analysis of nitrated proteins by nitrotyrosine-specific affinity probes and mass spectrometry. Anal Biochem 2003;320:214-22

Ohara A, Mizuno M, Danno G, Kanazawa K, Yoshioka T, Natake M. Mutagen formed from tryptophan reacted with sodium nitrite in acidic solution. Mutat. Res 1988;206:65-71

Paik DC, Ramey WG, Dillon J, Tilson MD. The nitrite/elastin reaction: implications for in vivo degenerative effects. Connect Tissue Res 1997;36:241-51

Paik DC, Dillon J, Galicia E, Tilson MD. The nitrite/collagen reaction: non-enzymatic nitration as a model system for age-related damage. Connect Tissue Res 2001;42:111-22

Paik DC, Saito LY, Sugirtharaj DD, Holmes JW. Nitriteinduced cross-linking alters remodeling and mechanical properties of collagenous engineered tissues. Conn Tissue Res 2006;47:163-76

Petersson AS, Steen H, Kalume DE, Caidahl K, Roepstorff P. Investigation of tyrosine nitration in proteins by mass spectrometry. J Mass Spectrom 2001;36:616-25

Pfeiffer S, Mayer B. Lack of tyrosine nitration by peroxynitrite generated at physiological pH. J Biol Chem 1998;273:27280-5

Pfeiffer S, Lass A, Schmidt K, Mayer B. Protein tyrosine nitration in cytokine-activated murine macrophages. J Bio Chem 2001;276:34051-8

Radi R. Nitric oxide, oxidants, and protein tyrosine nitration. 
Proc Natl Acad Sci USA 2004;101:4003-8

Sato E, Koyama S, Camhi SL, Nelson DK, Robbins RA. Reactive oxygen and nitrogen metabolites modulate fibronectin-induced fibroblast migration in vitro. Free Radic Biol Med 2001;30:22-9

Sell DR, Monnier VM. Structure elucidation of a senescence cross-link from human extracellular matrix. J Biol Chem 1989;264:21597-602

Sims TJ, Rasmussen LM, Oxlund H, Bailey AJ. The role of glycation cross-links in diabetic vascular stiffening. Diabetologia 1996;39:946-51

Sun W, Li F, Wang J, Zheng D, Gao Y. AMASS: software for automatically validating the quality of MS/MS spectrum from SEQUEST results. Mol Cell Proteomics 2004;3:1194-9

Thomas DD, Espey MG, Vitek MP, Miranda KM, Wink DA. Protein nitration is mediated by heme and free metals through Fenton-type chemistry: an alternative to the $\mathrm{NO} / \mathrm{O}_{2}$ - reaction. Proc Natl Acad Sci USA 2002;99:12691-6

Timpl R, Weidemann H, Van Delden V, Furthmayr H, Kuhn K. A network model for the organization of type IV collagen molecules in basement membrane. Eur J Biochem 1981;120: 203-11

Van der Vliet A, Eiserich JP, Halliwell B, Cross CE. Formation of reactive nitrogen species during peroxidase-catalyzed oxidation of nitrite. J Bio Chem 1997;272:7617-25
Viner RI, Ferrington DA, Williams TD, Bigelow DJ, Schoneich C. Protein modification during biological aging: selective tyrosine nitration of the SERCA2a isoform of the sarcoplasmic reticulum $\mathrm{Ca}^{2+}$-ATPase in skeletal muscle. Biochem $\mathrm{J}$ 1999;340:657-69

Vione D, Maurino V, Minero C, Pelizzetti E. New processes in the environmental chemistry of nitrite: nitration of phenol upon nitrite photoinduced oxidation. Environ Sci Technol 2002; 36:669- 76.

Wang Z, Paik DC, Del Priore LV, Burch RL, Gaillard ER. Nitrite-modified extracellular matrix proteins deleteriously affect retinal pigment epithelial cell function and viability: a comparison study with nonenzymatic glycation mechanisms. Curr Eye Res 2005;30:691-702

Whiteman M, Siau JL, Halliwell B. Lack of tyrosine nitration by hypochlorous acid in the presence of physiological concentrations of nitrite. J Biol Chem 2003;278:8380-4

Willard BB, Ruse CI, Keightley JA, Bond M, Kinter M. Sitespecific quantitation of protein nitration using liquid chromatography/tandem mass spectrometry. Anal Chem 2003; 75:2370-6

Winlove CP, Parker KH, Avery NC, Bailey AJ. Interactions of elastin and aorta with sugars in vitro and their effects on biochemical and physical properties. Diabetologia 1996;39: 1131-9 